\title{
Durability of Portland Concrete Containing Polymeric Fillers and Fly Ash
}

\author{
Witold BROSTOW ${ }^{1}{ }^{*}$, Nonso CHETUYA ${ }^{1}$, Osman GENCEL ${ }^{2}$, Hee Jae HONG ${ }^{1}$, \\ Noah MENARD ${ }^{3}$, Susmitha SAYANA ${ }^{1,4}$ \\ ${ }^{1}$ Department of Materials Science and Engineering, University of North Texas, 3940 North Elm Street, Denton, TX 76207, \\ USA \\ ${ }^{2}$ Civil Engineering Department, Faculty of Engineering, Bartin University, 74100 Bartin, Turkey \\ ${ }^{3}$ Veritas Testing \& Consulting, LLC, 800 S. Loop 288 \#396, Denton, TX 76205, USA \\ ${ }^{4}$ School of Engineering and Applied Sciences, Columbia University, 500 W. 120th St, New York, NY 10027, USA \\ crossref http://dx.doi.org/10.5755/j01.ms.26.1.21367
}

Received 01 August 2018; accepted 15 December 2018

\begin{abstract}
Portland concrete suffers in service brittle failure, extensive crack propagation, and wear rates increasing with time. In spite of all the effort expended, these problems persisted when we had started our project. We used several polymeric fillers and fly ash. Higher compressive moduli than the starting concrete are seen for some compositions, the highest for $5 \%$ of one of the polymers $+5 \%$ fly ash. The same composition has the lowest Taber abrasive wear loss. All composites show lower wear loss values than Portland concrete. After 25 days of acidic degradation in 4.0 molar aq. $\mathrm{HCl}$, the starting Portland concrete suffers stronger degradation that our composites. Polymer swelling mitigates acidic degradation. Repetitive freeze-thaw cycles between $15 \mathrm{oF}$ and $85 \mathrm{oF}$ show disappearance of the deep voids present before the first cycle in our composites but not in the Portland cement. While the use of fly ash mitigates contamination of the environment, it is the combination of fly ash with polymers which provides significantly improved properties - tribological, chemical and mechanical ones - of the Portland concrete.

Keywords: concrete embrittlement, concrete modification, concrete tribology, concrete abrasion.
\end{abstract}

\section{INTRODUCTION}

Concretes have been used for thousands of years, first mineral concretes, above all in construction and also as road and bridge materials [1,2]. Mineral concretes can carry huge loads. However, these concretes are brittle and prone to crack formation - a potential problem in all cases, and a dramatic one during earthquakes [3]. When a crack appears, it can be filled with a polymer - much more flexible and resistant to deformation [4-6]. Bitumen has also been used for improving properties of mineral concrete as a road material [7]. The fact that polymers are viscoelastic [2,8] is actually helpful here; polymeric chains can adapt their molecular conformations under the application of a force-while inorganic constituents can only respond by fracture.

We also note that various waste materials including waste marble or fly ash have been used as fillers [9-12]. It is for this reason that fly ash reactivity in hydrating cement has been studied by neutron scattering [13]. Finally, polymer-based concretes are also being used and have been compared to mineral ones $[14,15]$.

We felt that this situation behooves us to modify Portland concrete - to significantly mitigate the drawbacks known for centuries. Longer durability of structures made with Portland concrete should also contribute to sustainability. Reviewing the extensive literature, we have found that the remedies tried involved inorganic compounds - actually not surprising given the chemical nature of the Portland concrete itself. Inorganic compounds are not viscoelastic; under the application of a force the Portland concrete can either 'survive' or fracture into pieces. This while the key applications of concretes are based on their capability to carry large loads. This led us to recognizing that polymeric chains - with their capability to modify macromolecular conformations under the applications of a force - have a dramatic advantage over non-viscoelastic materials. Moreover, as discussed by Briscoe and Sinha [16], in the contact of moving surfaces there is formation of relatively much softer 'third body' particles in the case of polymers - while ceramic and other inorganic particles are hard and highly abrasive.

We have applied several polymers as fillers in order to study their effect on the mineral concretes. We also kept the sustainability approach such that potential waste will find useful application. Thus, our fillers contain in turn several polymers and fly ash. The advantages of each such combined filler is highlighted in its performance in the comprehensive testing - over a course of time and use. One of the pertinent properties here is abrasion $[9,16,17]$. Interesting attempts to relate abrasion to mechanical properties - flexural modulus in particular-have been reported $[16,17]$.

\section{EXPERIMENTAL}

Portland concrete was made from Portland cement, with one part the cement, 2 parts sand, and 3 parts gravel. The starting masses varied between 22 and $25 \mathrm{~g}$. We recall that Portland cement is hydraulic, it sets and becomes adhesive

\footnotetext{
* Corresponding author. Tel.: +1-940-565-435; fax: +1-940-565-4422.

E-mail address: wkbrostow@gmail.com (W. Brostow)
} 
due to a chemical reaction between the dry constituents and water. Commercial Quikrete 5000 concrete mix with the water to cement ratio of $77.3 \mathrm{ml}$ per kilogram was used. Four main polymers were chosen to be incorporated into the concretes composition: Rovorene 6090, 6017, 403, and Tylac. These polymers involve a strong molecular backbone such as acrylic and were the cheapest among their category. The polymers were used to replace up to 10 percent of the concretes composition; example: $90 \mathrm{wt} . \%$ Portland concrete, $5 \%$ Rovorene 6090, 5 \% fly ash. Each sample was prepared under 10 minutes and was allowed to cure for 7 days. Four main tests were conducted on these chosen concrete composites. The first was compression testing, to ensure that the composites have a similar elastic modulus to the control, that is neat concrete. Following these tests and comparison were abrasion testing, crack propagation testing, and chemical degradation testing.

Compression testing (elastic modulus): a MTS machine was used. The dimensions of the molds were $12.7 \mathrm{~mm} \times 12.7 \mathrm{~mm} \times 25.4 \mathrm{~mm}$, according to the appropriate ASTM D-695 standard. All materials were allotted a total of 7 days to cure. While most of curing mineral concretes occurs in the beginning of the process, the entire curing takes years, with thermal effects detectable by microcalorimetry two years since the beginning of the process [2]. However, curing of epoxies and other polymers is much faster [18]; hence seven days curing cycles. The results after the seven days will be used for comparisons.

Abrasion testing: samples were molded into a disk and placed on a Taber Abrader. This machine abrades the disk at a specific angle for 500 cycles. As the turntable rotates, the wheels are driven by the sample in opposite directions about a horizontal axis displaced tangentially from the axis of the sample. One abrading wheel rubs the specimen outward toward the periphery while the other inwards toward the center. Before and after testing, the weight loss caused by debris formation is recorded.
Chemical degradation tests: samples were placed in 4.0 molar aq. $\mathrm{HCl}$ solution for a specified amount of time. Specimens were dried for a full 24 hours and then weighed every 1, 4, 9, 16, and 25 days. After weighing, the samples were placed back into the solution until the next test date. The difference in sample weights before and after exposure to the $\mathrm{HCl}$ solution can suggest possible chemical degradation, perhaps implying some molecular vulnerability of the polymer concrete as a filler to the mineral concrete cracks and gaps.

Crack propagation tests: the crack growth in concretes was measured in repeated freeze-thaw cycles to simulate what happens to concrete during extreme temperatures and in industrial applications. SEM micrographs were taken of the samples before and after those cycles for 3 weeks with a minimum of 3 cycles per week. Thus, there was the total of 9 cycles. The freezing temperature was set to $-9.4{ }^{\circ} \mathrm{C}$ and the thawing temperature to $29.4^{\circ} \mathrm{C}$. Weight loss was recorded in each cycle.

Completion of the above tests for various compositions and comparing the results to those for neat concrete should enable optimization for the successful crack healing of mineral concretes. We recall that polymer concretes have been compared to mineral ones [14].

\section{RESULTS AND DISCUSSION}

\subsection{Compression testing results}

Compressive moduli of elasticity are compared in Fig. 1. Compression testing was aimed at elimination of compositions which did not have moduli comparable or higher than the neat mineral concrete. As seen in Fig. 1, the top peformers contained: a-90 wt.\% Portland concrete, $5 \%$ Rovorene 6090, $5 \%$ fly ash; b-90\% Portland concrete, $5 \%$ Rovorene 6017, $5 \%$ fly ash. Compositions based on these results were then tested for abrasion resistance.

\section{Modulus of Elasticity}

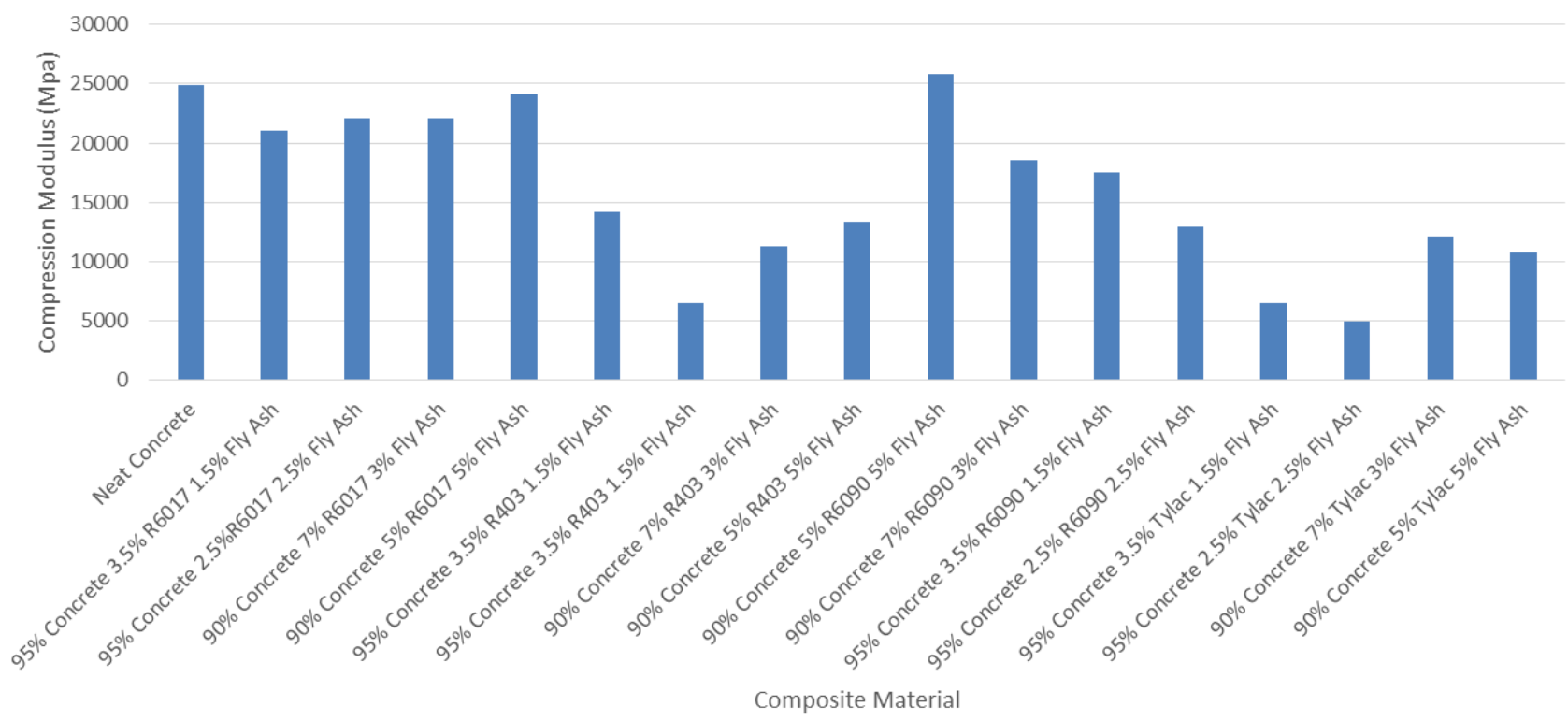

Fig. 1. Compressive moduli of elasticity 


\subsection{Abrasion testing}

The results are summarized in Fig. 2. Since the starting masses of the samples were all within a relatively narrow range, the absolute weight losses are meaningful.

The original weights of the specimens subjected to abrasion testing were comparable. We see that the neat mineral concrete (control) is the worst by far from the point of view of abrasion. The second worst contains $2.5 \mathrm{wt} . \%$ Rovorene 6090 and $2.5 \%$ fly ash. The overall winner is the one in the middle of Fig. 2, with $5 \%$ Rovorene 6017 and $5 \%$ fly ash; its weight loss of 4 grams is less than $1 / 3$ of the abrasion loss of the control Portland concrete.

\subsection{Acidic degradation}

Results of acidic degradation over a period of 25 days are presented in Fig. 3. Again, since the starting masses of the samples were all within a relatively narrow range, the absolute weight losses are meaningful.
The worst from this point of view is neat concrete with the weight loss of $\approx 0.24 \mathrm{~g}$ by Day 25 . We can see that initially neat concrete had the best performance, or the least weight loss. However, as time goes on, the concrete matrix becomes more susceptible to degradation than the polymer containing concretes. The latter were losing the weight initially, but then we see a more stable or slower weight loss than the neat concrete. These results can be explained by swelling in the polymer containing concretes - resulting in improved protection against the acidic degradation.

\subsection{Crack propagation testing}

The results in the form of scanning electron micrographs are presented in Fig. 4 for neat concrete, in Fig. 5 for specimens with Rovorene 6017 and fly ash, in Fig. 6 for materials with Rovorene 6090 and fly ash, in Fig. 7 for specimens with fly ash only.

We see in Fig. 4 that all open deep gaps become much shallower as a result of the repetitive freeze-thaw cycles between $-9.4{ }^{\circ} \mathrm{C}$ and $29.4{ }^{\circ} \mathrm{C}$.

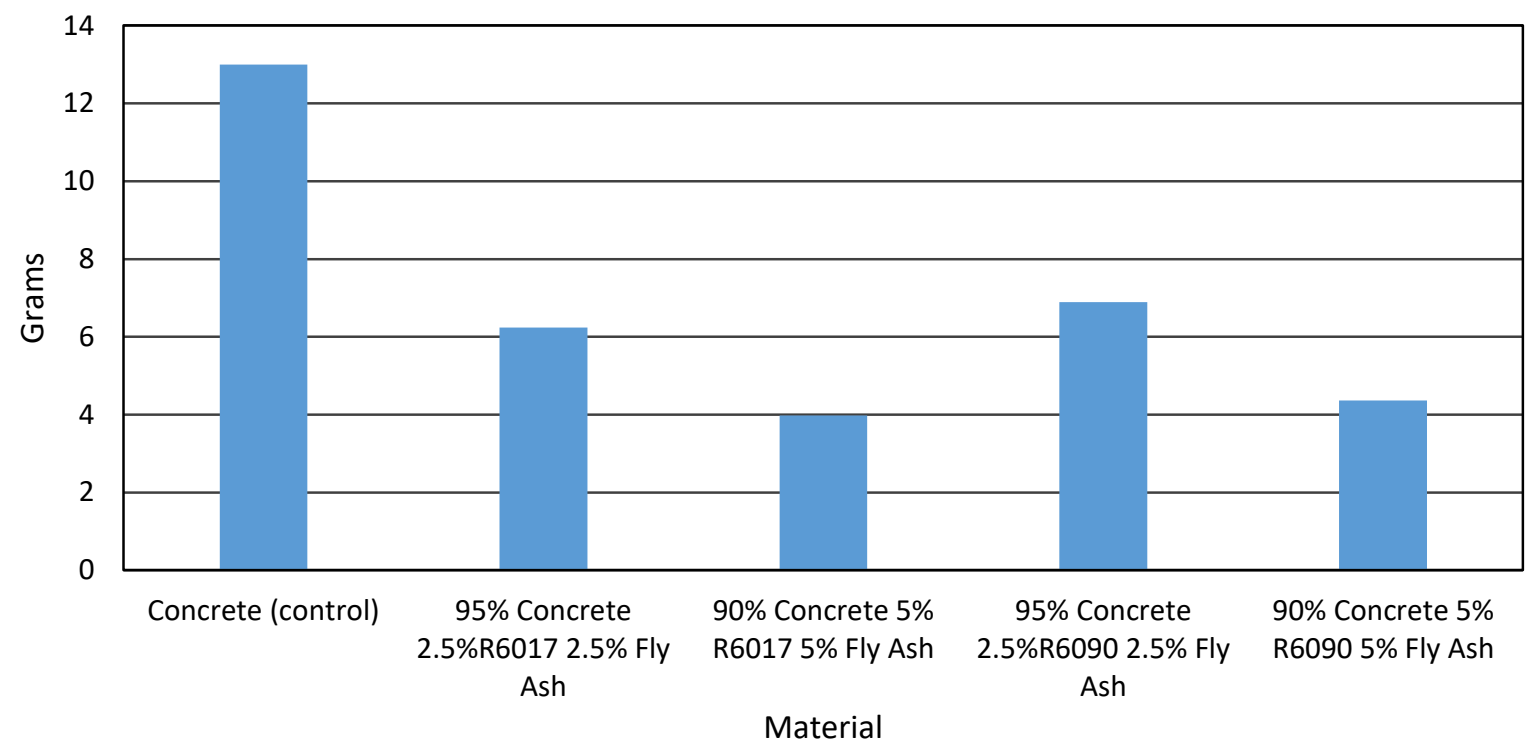

Fig. 2. Abrasive weight loss results

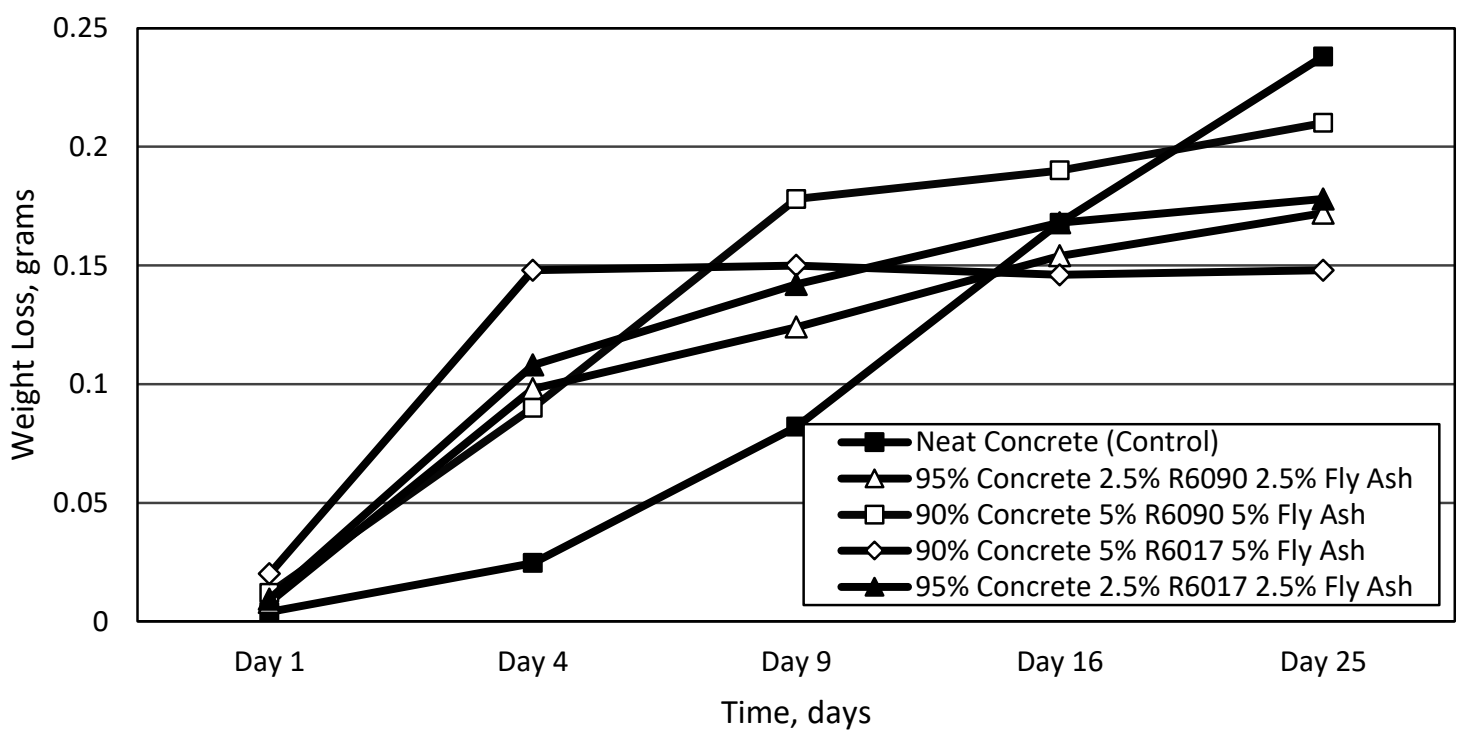

Fig. 3. Acidic degradation in 4.0 molar aq. $\mathrm{HCl}$ of selected compositions as a function of time 


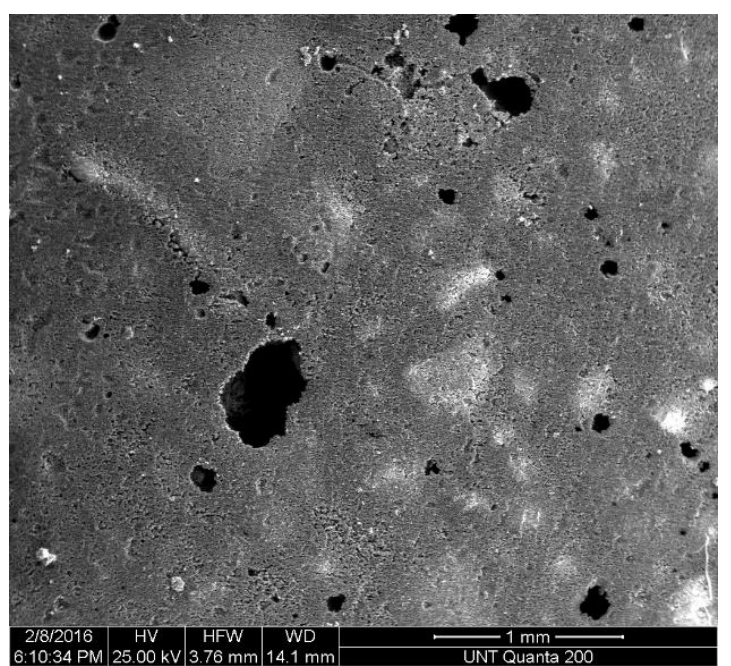

a

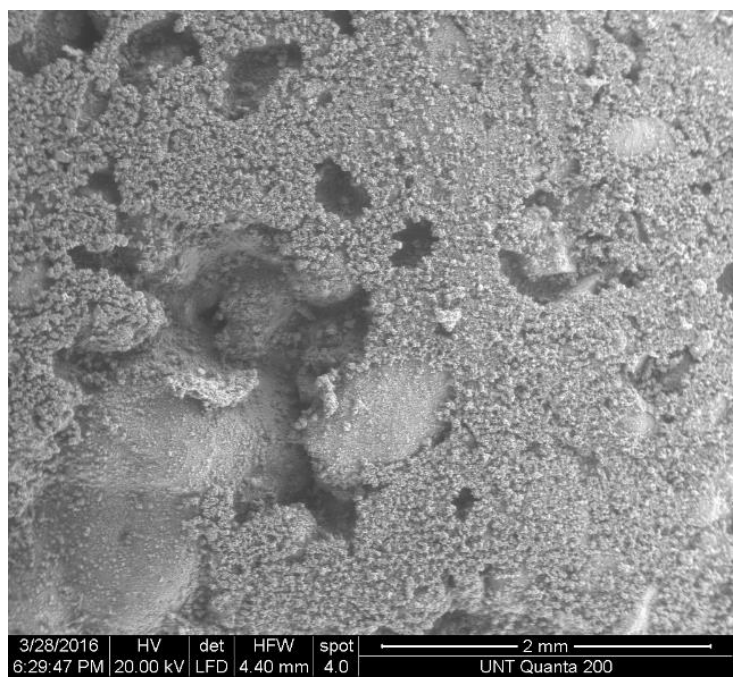

b

Fig. 4. SEM observations for neat mineral concrete: a-before crack propagation; $b$-after crack propagation causes by 3 weeks of freeze-thaw cycles

However, the two-dimensional surface areas of the gaps are not smaller than before. In Fig. 5 we display SEM micrographs for composites containing $5 \mathrm{wt} \%$ Rovorene 6017 and $5 \%$ fly ash, again before and after freeze-thaw cycles.

We see in Fig. 5 a a cloudy and multi-texture coating of the gaps before crack propagation. There are large deep voids and lack of the uniformity of the sample surface. Fig. 5 b, with a 10 times larger magnification (compare the scales at the bottom of both micrographs) show practically complete disappearance of the deep voids, in spite of the fact that crack propagation has taken place.

Since we work with two kinds of Rovorene, in Fig. 6 we show micrograph for composites containing 5 wt. $\%$ Rovorene 6090 and 5 wt.\% fly ash.

We see in that deep gaps and cracks from Fig. 6 a are covered and filled in Fig. 8 b. Fig. 8 b also shows an apparent texture difference in the spaces not affected by the cracks. We also see in Fig. 8 b some remaining gaps and small dot-like holes throughout the resulting product after crack propagation. We now consider results for composites containing 5 wt.\% fly ash only, without the Rovorenes; see Fig. 7.

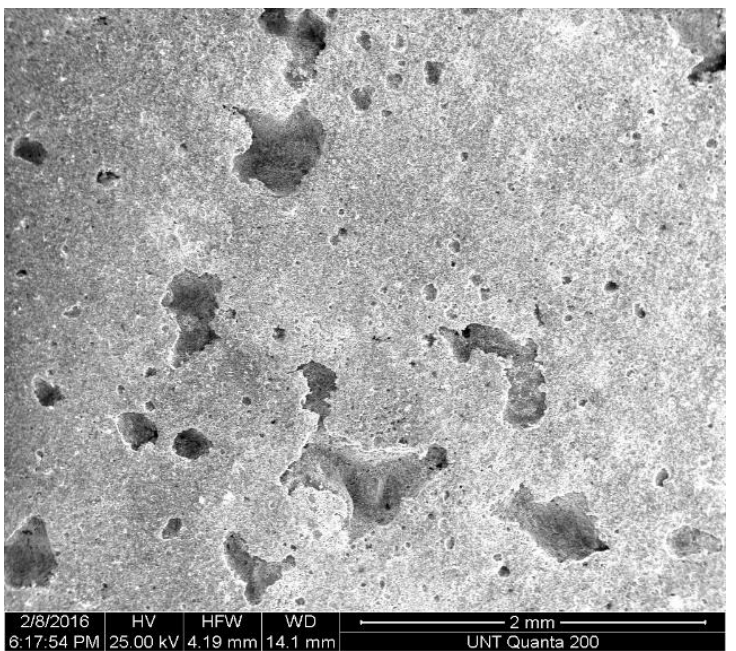

a

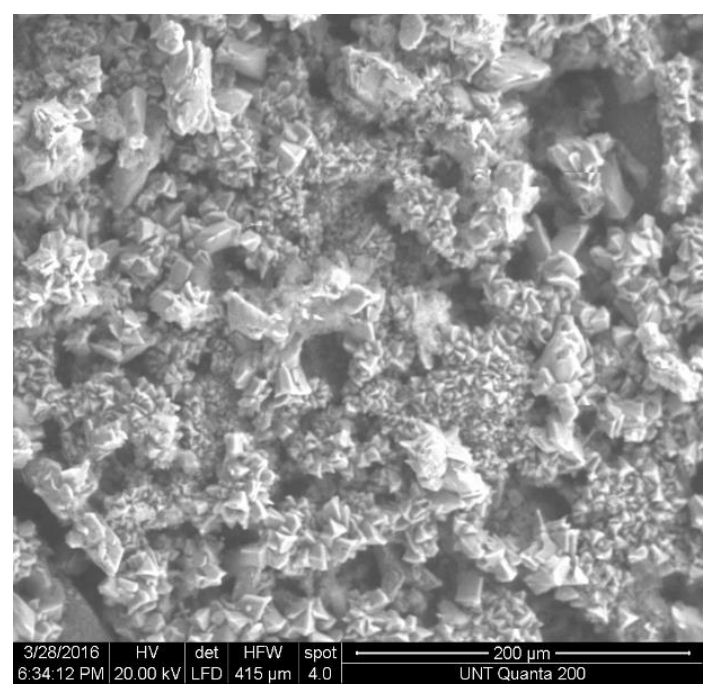

b

Fig. 5. SEM for materials containing $5 \mathrm{wt} \%$ Rovorene 6017 and $5 \%$ fly ash: a-before crack propagation testing; b a-after crack propagation testing. Note the change of scale between $\mathrm{a}$ and $\mathrm{b}$

We find that gaps and cracks seen in Fig. 7 a have been successfully filled by fly ash in Fig. 7 b. Thus, all composites containing a polymer and/or fly ash show significant improvement of their surfaces after 9 freezethaw cycles. We recall here the statement by Song and coworkers [19]: "freeze-thaw damage and steel corrosion pose threats to the strength of concrete. Furthermore, ice formation on concrete road-surfaces greatly increases injury and fatality rates". Clearly the property changes caused by multiple freeze-thaw cycles strongly depend on the composition of the concrete.

We can see a great reduction of weight loss in abrasion testing with just a $5 \%$ addition of the polymer. With the starting sample masses between 22 and 25 grams, in two cases in Fig. 2 we have seen 5 grams lost.

This can be compared to 13 grams lost by the control concrete sample without additives, thus some $50 \%$ loss. 


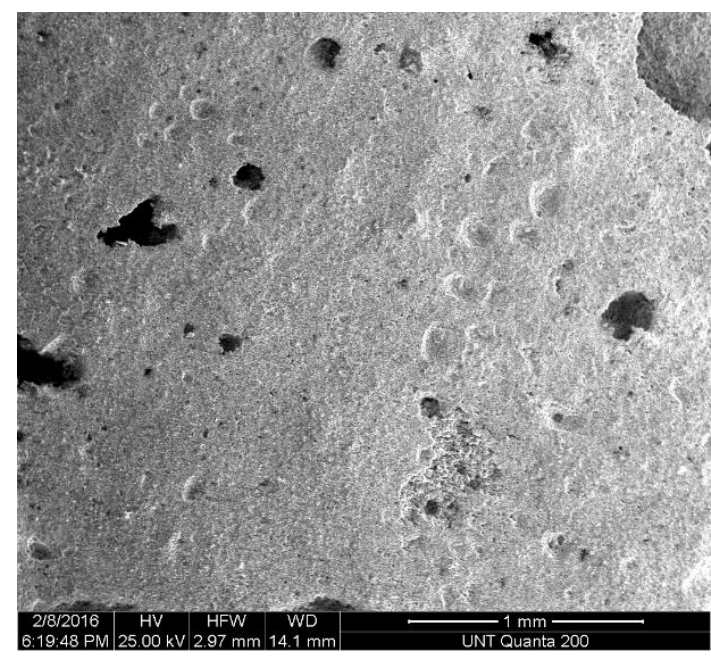

a

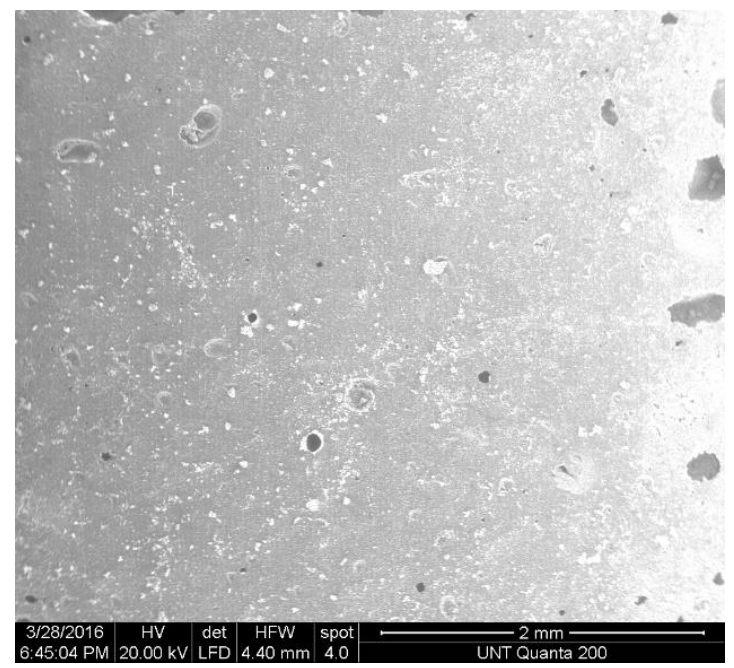

b

Fig. 6. SEM observations for specimens containing 5 wt. $\%$ Rovorene 6090 and $5 \%$ fly ash: a-before freeze-thaw cycles; $\mathrm{b}$ - after freeze-thaw cycles

A possible explanation is that the polymer is acting as a friction reducer while the samples are being abraded [16]. Fig. 3 tells us that the samples with additives placed into an $\mathrm{HCl}$ aq. acidic bath initially were all losing weight. However, after 10 days or so, two of them began to maintain a consistent weight. By contrast, neat concrete was losing weight continuously and at 25 days there are no signs of mitigation of this process. We recall a study of concretes one without and one with steel fibers - subjected to freezethaw cycles in a $\mathrm{NaCl}$ solution by Gunasekaran and coworkers [20]. In both cases the impact resistance was reduced.

The polymer in the composite concrete seems to be absorbing the water from the acidic solution and filling the pores within the concrete as it swells. Pore structure of polymer-modified Portland cement pastes was studied by small-angle X-ray and neutron scattering by Castaño and his colleagues [21]. The pores reduce the total surface area of the concrete and making the concrete less susceptible to corrosion and degradation in an acidic environment.

This might be an example of material self-organization as discussed by Desai and Kapral [22].

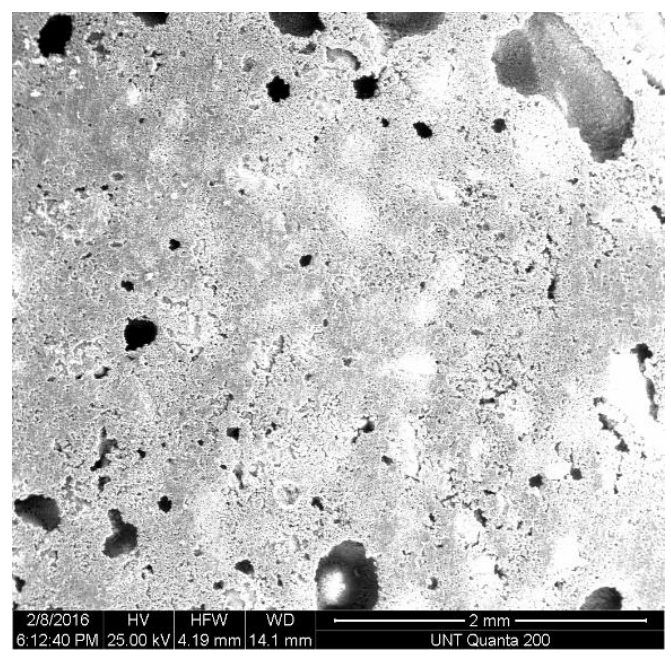

a

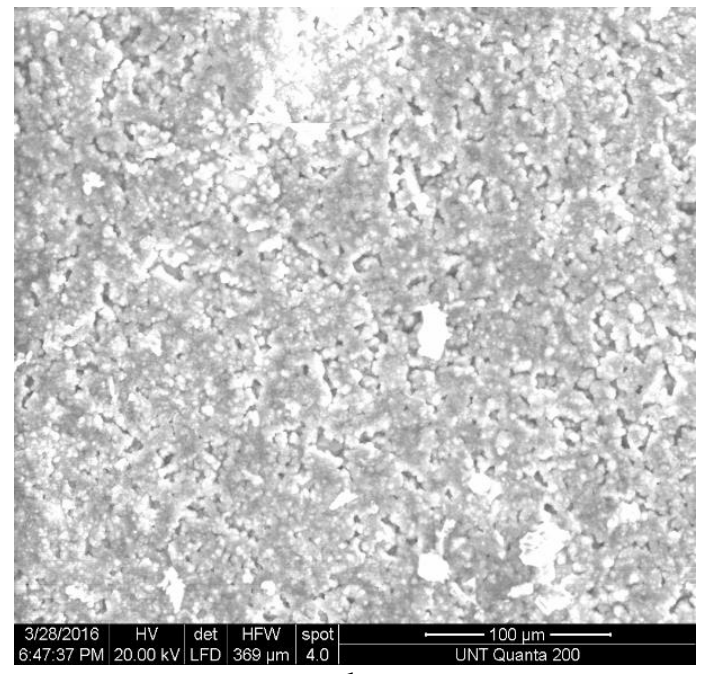

b

Fig. 7. SEM observations for specimens containing $5 \mathrm{wt} \%$ fly ash; as before: a-micrograph is for a composite before freeze-thaw cycles; $b$ - one after those cycles

SEM photos pertaining to the freezing-thawing cycles show us that the composite concrete is more homogenous in structure then the neat concrete.

This applies also after the crack propagation testing suggesting that the composite structure may be more stable under thermal and mechanical stresses resulting from varying the environment temperatures.

In earlier work on concretes we have included clinoptilolite [23], a natural mineral available among others in California and also around the shores of the Aegean Sea. Significant improvement of the compressive strength was found after such concretes were subjected to $400{ }^{\circ} \mathrm{C}$ or $500{ }^{\circ} \mathrm{C}$ treatments. Production of fly ash poses a problem since in a variety of locations around the world fly ash simply becomes waste. We demonstrate how fly ash can be used to improve properties of Portland concrete. We also recall how Falayi and colleagues [24] have found a good use for desilicated fly ash lime. It seems we have here examples of the "thrash to treasure" approach. Interestingly, the results reported above show that a combination of a polymer and fly ash provides significantly more improvement of several properties than either of these additions alone. 


\section{CONCLUSIONS}

Higher compressive moduli than the starting concrete are seen for some compositions, the highest for $5 \%$ of one of the polymers $+5 \%$ fly ash. The same composition has the lowest Taber abrasive wear loss. All composites show lower wear loss values than Portland concrete. After 25 days of acidic degradation in 4.0 molar aq. $\mathrm{HCl}$, the starting Portland concrete suffers stronger degradation that our composites. Polymer swelling mitigates acidic degradation. Repetitive freeze-thaw cycles between $15 \mathrm{oF}$ and $85 \mathrm{oF}$ show disappearance of the deep voids present before the first cycle in our composites - but not in the Portland cement. While the use of fly ash mitigates contamination of the environment, it is the combination of fly ash with polymers which provides significantly improved properties tribological, chemical and mechanical ones - of the Portland concrete.

\section{Acknowledgments}

Partial financial support for one of us (S.S.) by the Texas Academy of Mathematics and Science (TAMS), Denton, Texas, is acknowledged. Helpful comments of a reviewer of our manuscript are appreciated.

\section{REFERENCES}

1. Davidovits, J. Geopolymers: Man-Made Rock Geosynthesis and the Resulting Development of Very Early High Strength Cement Journal of Materials Education 16 1994: pp. 91.

2. Brostow, W., Hagg Lobland, H.E. Materials: Introduction and Applications, John Wiley \& Sons, Hoboken, NJ 2017.

3. Castaño, V.M., Martinez, L. The Role of Materials Science after the Mexico City Earthquakes in 1985 Journal of Materials Research 5 1990: pp. $658-665$.

https://doi.org/10.1557/JMR.1990.065

4. Morlat, R., Orange, G., Bornal, Y., Godard, P. Reinforcement of Hydrated Portland Cement with High Molecular Mass Water-Soluble Polymers Journal of Materials Science 42 2007: pp. 4858-4859. https://doi.org/10.1007/s10853-006-0645-z

5. Pellegrino, C., da Porto, F., Modena, C. Experimental Behaviour of Reinforced Concrete Elements Repaired with Polymer-Modified Cementicious Mortar Materials and Structures 44 2011: pp. $517-527$.

https://doi.org/10.1617/s11527-010-9646-0

6. Pelissier, F., Zavarise, N., Longo, T.A., Bernardin, A.M. Concrete Made with Recycled Tire Rubber: Effect of Alkaline Activation and Silica Fume Addition Journal of Cleaner Production 19 2011: pp. $757-763$. https://doi.org/10.1016/j.jclepro.2010.11.014

7. López-Paz, J., Gracia-Fernández, C., Gómez-Barreiro, S., López-Beceiro, J., Nebreda, J., Artiaga, R. Study of Bitumen Crystallization by Temperature-Modulated Differential Scanning Calorimetry and Rheology Journal of Materials Research 27 2012: pp. $1410-1416$. https://doi.org/10.1557/jmr.2012.73

8. Oyen, M.L., Cook, R.F. Load-Displacement Behavior During Sharp Indentation of Viscous-Elastic-Plastic Materials Journal of Materials Research

2003: pp. $139-150$.

https://doi.org/10.1557/JMR.2003.0020

9. Siddique, R., Khatib, J.M. Abrasion Resistance and Mechanical Properties of High-Volume Fly Ash Concrete Materials \& Structures 43 2010: pp. 709-718. https://doi.org/10.1617/s11527-009-9523-x
10. Uygunoglu, T., Topcu, I.B., Gencel, O., Brostow, W. The effect of Fly Ash Content and Types of Aggregates on the Properties of PreFabricated Concrete Interlocking Blocks (PCIBs) Construction and Building Materials 29 2012: pp. $180-187$.

https://doi.org/10.1016/j.conbuildmat.2011.12.020

11. Gencel, O., Ozel, C., Koksal, F., Erdogmus, E., MartinezBarrera, G., Brostow, W. Properties of Concrete Paving Blocks Made with Waste Marble Journal of Cleaner Production 21 2012: pp. $62-70$. https://doi.org/10.1016/j.jclepro.2011.08.023

12. Dobiszewska, M. Waste Materials Used in Making Mortar and Concrete Journal of Materials Education 39 2017: pp. $133-156$.

13. Bumrongjaroen, W., Livingston, R.A., Neumann, D.A., Allen, A.J. Characterization of Fly Ash Reactivity in Hydrating Cement by Neutron Scattering Journal of Materials Research 24 2009: pp. $2435-2448$. https://doi.org/10.1557/jmr.2009.0267

14. Martinez-Barrera, G., Vigueras-Santiago, E., Gencel, O., Hagg Lobland, H.E. Polymer Concretes: A Description and Methods for Modification and Improvement Journal of Materials Education 33 2011: pp. 37-52.

15. Brostow, W., Chetuya, N., Hnatchuk, N., Uygunoglu, T. Reinforcing Concrete: Comparison of Filler Effects Journal of Cleaner Production 112 2016: pp. 2243-2248. https://doi.org/10.1016/j.jclepro.2015.09.105

16. Briscoe, B.J., Sinha, S.K. Wear of Polymers Proceedings of the Institution of Mechanical Engineers Part J: Journal of Engineering Tribology 216 2002: pp. 401-413. https://doi.org/10.1243/135065002762355325

17. Atis, C.D., Çelik, O.N. Relation between Abrasion Resistance and Flexural Strength of High Volume Fly Ash Concrete Materials \& Structures 35 2002: pp. 257-260. https://doi.org/10.1007/BF02533087

18. Bilyeu, B., Brostow, W., Menard, K.P. Epoxy Thermosets and Their Applications. III. Kinetic Equations and Models Journal of Materials Education 23 2001: pp. 189-204.

19. Song, J., Zhao, D., Han, Z., Xu, W., Lu, Y., Liu, X., Liu, B., Carmalt, C.J., Parkin, I.P. Super-robust Superhydrophobic Concrete Journal of Materials Chemistry A 5 2017: pp. 14542. https://doi.org/10.1039/c7ta03526h

20. Gunasekaran, M., et al. Impact Response and Strength Reliability of Green High Performance Fibre Reinforced Concrete Subjected to Freeze-thaw Cycles in $\mathrm{NaCl}$ Solution Materials Science (Medziagotyra) 23 (4) 2017: pp. 384-388. https://doi.org/10.5755/j01.ms.23.4.17334

21. Castaño, V.M., Schmidt, P.W., Hörnis, H.G. Small-angle Scattering Studies of the Pore Structure of Polymer-Modified Portland Cement Pastes Journal of Materials Research 5 1990: pp. $1281-1284$. https://doi.org/10.1557/JMR.1990.1281

22. Desai, R., Kapral, R. Dynamics of Self-organized and Selfassembled Structures Cambridge University Press, Cambridge - New York, 2009.

23. Beycioglu, A., Aruntas, H.Y., Gencel, O., Hagg Lobland, H.E., Samandar, A., Brostow, W. Effect of Elevated Temperatures on Properties of Blended Cements with Clinoptilolite Materials Science (Medziagotyra) 22 (4) 2016: pp. 548-552. https://doi.org/10.5755/j01.ms.22.4.13354

24. Falayi, T., Okonta, F.N., Ntuli, F. Kinetics Mechanism of Desilicated Fly Ash Lime Consumption Materials Science (Medziagotyra) 24 (2) 2018: pp. $192-196$ http://dx.doi.org/10.5755/j01.ms.24.2.14284 